\title{
RACIONALIDAD FORMAL O RACIONALIDAD HERMENÉUTICA PARA EL DERECHO DE LAS SOCIEDADES COMPLEJAS ${ }^{1}$
}

Carlos María Cárcova ${ }^{2}$

Como citar este documento / How to cite this document (informe a data atual de acesso / inform the current date of access):

CÁRCOVA, Carlos María. Racionalidad formal o racionalidad hermenéutica para el derecho de las sociedades complejas. Revista da Faculdade de Direito UFPR, Curitiba, PR, Brasil, v. 64, n. 2, p. 211-226, maio/ago. 2019. ISSN $2236-7284$. Disponível em: https://revistas.ufpr.br/direito/article/view/68281. Acesso em: 31 ago. $2019 . \quad$ DOI: http://dx.doi.org/10.5380/rfdufpr.v64i2.68281.

\section{LA RACIONALIDAD Y SUS FUNDAMENTOS EPISTÉMICOS}

Más allá de usos metafóricos, lo que resulta racional en el campo del conocimiento es el entramado de conceptos, prácticas y elaboraciones que responden a ciertos fundamentos epistémicos. Es conocido que la epistemología como teoría del conocimiento científico, no como filosofía, tiene una historia relativamente reciente. Para muchos autores se desarrolla en línea con el pensamiento moderno y en su primera versión con apoyo en el método empírico (Galileo/Bacon), la filosofía de Descartes y la física de Newton. El exitoso despliegue de las ciencias naturales desde finales del s. XVII a la actualidad, le otorgó preeminencia a un modo de pensar la producción de conocimientos que, desde la física, se extendió al resto de las ciencias naturales y conquistó, más tarde también a buena parte de las ciencias sociales.

Basta recordar que Auguste Comte, el padre de la sociología, denominaría a una obra principal, “Tratado de física social”. Su idea, y la de otros científicos sociales, era que resultaba necesario basar la búsqueda del conocimiento social en el método empírico, en la observación y la experimentación y en las premisas del fisicalismo, el causalismo y el monismo metódico, compartiendo esa perspectiva con John Stuart Mill. Resulta así construida una mirada acerca del conocimiento y la racionalidad, que adopta el nombre de explicativismo/positivismo y que adquiere sus desarrollos más elaborados dentro del empirismo lógico con Carl Hempel y en un registro más autónomo, con Karl Popper.

\footnotetext{
${ }^{1}$ Discurso proferido na sessão solene do Conselho Universitário da UFPR - Universidade Federal do Paraná -, no Salão Nobre da Faculdade de Direito, por ocasião da outorga do título de doutor honoris causa ao autor (Professor Doutor Carlos María Cárcova), em 17 de junho de 2019.

2 Profesor Emérito - Universidad de Buenos Aires (UBA).
} 
Pero a finales del siglo XIX surge otra corriente epistémica que se nutre de influencias postkantianas y post-hegelianas; entre sus integrantes se encuentran figuras de gran porte como Dilthey, Simmel, Weber, Windelband, Rickert, Croce y Collingwood, entre otros. Ellos rechazan las premisas monistas y sostienen la especificidad del conocimiento social que fundan en otras nociones; comprensión, empatía, tipos ideales de conducta, socialización, cuestión semántica, construcción del sentido.

Esta corriente que también incluye a positivistas críticos como John Dray o Elizabeth Anscombe, termina denominándose “comprensivismo” y confronta en el campo de las ciencias sociales con el explicativismo, en una pugna aun no superada, que lleva más de dos siglos.

Por último, a mediados del siglo pasado surge una tercera perspectiva epistémica genéricamente denominada como "nueva ciencia” o constructivismo, que introduce variaciones y problemáticas de nuevo tipo, de la mano de autores como Wiener, Bigelow, Von Foerster, Von Glasserman, Varela y Maturana y Luhmann, entre otros. Aquellas problemáticas refieren a la idea de propósito, función, sistema, retroalimentación, autopoiésis, teleología, incertidumbre, complejidad o riesgo.

Frente a este matizado panorama, es posible preguntarse: ¿cuál es el tipo de racionalidad que el complejo fenómeno de la juridicidad demanda y cuál ha demandado en el pasado? En este punto seguramente las respuestas serán discrepantes, según se trate de distintas escuelas de pensamiento jusfilosófico. Sospecho, sin embargo, que podrían ponerse de acuerdo en que en los últimos treinta años, para poner una fecha aproximada, se ha producido un cambio, una mutación en relación con los criterios de racionalidad y las bases epistémicas, que al derecho conciernen.

Intentaré probarlo con referencias necesariamente esquemáticas.

\section{2 ¿CUÁL DE LOS KELSEN?}

Ciertamente los jusnaturalistas, tanto en su versión objetivista, medieval y religiosa, cuanto en su versión subjetivista, racionalista y utilitarista, tienen el mérito de haber luchado denodadamente para mantener en la agenda de los juristas los temas de la legitimidad y la justificación. Durante las primeras décadas del siglo XX parecía que habían perdido esa batalla, a expensas de la impronta kelseniana, que tuvo y mantuvo una fuerte preponderancia teórica. Pero a partir de los60’ del siglo 
pasado aquellos temas de la legitimidad y la justificación, quizás resemantizados, probablemente en términos de "los derechos humanos” están en discusión permanente en todo el mundo, aunque por lo general, habiendo perdido sus envolturas metafísicas.

Pero volvamos a Kelsen y su concepción del derecho. La visión canónica acerca de este autor, por muchas razones emparentado en diversos aspectos con el paleo positivismo, nos presenta una idea de derecho como ciencia formal, ajena a los contenidos de las normas, entre las que se establecen relaciones de jerarquía y procedimiento. El derecho sería un tipo de conocimiento avalorativo, basado en una premisa cognitiva, “la gründnorm” de la cual toda validez sería inferida. El derecho resultaría políticamente neutral y decididamente autónomo, en relación con la moral y con el mundo del ser, con el mundo de la facticidad y, por ello, diverso de las ciencias sociales que se ocupan de la conducta humana, de manera ajena a sus dimensiones normativas, de manera, diría Kelsen, causal y no imputativa.

Antes de mostrar que contemporáneamente lo jurídico parece definirse por el lado de los derechos y no de las prohibiciones, me gustaría señalar que la lectura deconstructiva de la versión canónica, nos muestra a otro Kelsen, sorprendentemente más político y menos formalista. Casi como un hermenéutico crítico. No puedo aquí desarrollar exhaustivamente esta otra mirada, por lo que aludiré a algunas cuestiones incluidas en la teoría que parecen contradictorias con lo señalado anteriormente y que me resisto a suponer que constituyen errores, inadvertencias, o simples recursos tendientes a preservar la coherencia de la teoría, puesto que Kelsen fue durante toda su larga vida, un hombre de gran honestidad intelectual.

La cuestión más importante, en mi opinión, concierne a la teoría de la norma como marco abierto de posibilidades. A través de ella la voluntad del juez (facticidad) se vuelve necesariamente constitutiva en el proceso de adjudicación, tanto como la voluntad del intérprete en general (legislador) al aplicar la norma constitucional. La actividad de los operadores se torna paradigmáticamente política, entendiendo este término como selección preferencial de finalidades sociales. Otro ejemplo más chocante con sus premisas formalistas, es el de su concepción de la norma alternativa. 
Sumemos su teoría de la “desuetudo” y de las lagunas (conf. R. Guibourg) ${ }^{3}$ y finalmente, el giro copernicano que introduce Kelsen en su teoría, poco antes de su muerte, al explicar con precisión y claridad que la naturaleza epistémica de la norma fundamental no es la una hipótesis cognitiva, como sostuviera durante más de 40 años, sino la de una "ficción completa” en el sentido tematizado en su "Tratado del como si”, por Hans Vaihinger. Con los elementos referidos, puede concluirse que por entre brumas axiomáticas se atisba la imagen de un hermenéutico.

Ya Tullio Ascarelli en su conocido ensayo “Antígona y Porzia” había mostrado el papel preponderante del intérprete. En un sentido semejante, dos autores contemporáneos, Jack Balkin y Sanford Levinson, han conceptualizado al derecho como una "performing arts". El derecho seria como una partitura musical, un guión cinematográfico, una obra de teatro o una Constitución. Fenómenos que requieren actualizaciones de sentido, requieren al autor y además al intérprete y por cierto a la audiencia que co-actúa, intersubjetivamente, porque celebra o rechaza, aplaude o silba.

¿Podemos pensar que el tránsito de un ordenamiento jurídico pensado como prohibición y sanción, hacia otro pensado como organización de facultades y de derechos, ha puesto en juego una nueva racionalidad jurídica?

Si fuera así, ¿esa racionalidad está más vinculada con una tarea argumentativa basada en convenciones o con una tarea hermenéutica? Y en ese caso, ¿quiénes y cuántos son los intérpretes?

Tal como nosotros lo apreciamos -volveremos sobre el asunto- la interpretación es un acto complejo, heurístico, hermenéutico, político y cultural, que carece de resultados unívocos. No hay verdad en las sentencias. A lo más, verosimilitud ${ }^{4}$.

Y bien, ante tan severos interrogantes, ¿¿cuál de los Kelsen posibles resulta más adecuado?

\footnotetext{
${ }^{3}$ V. “Derecho, sistema y realidad”, Ed Astrea, Bs. As., 2010.

4 “La verdad de la verdad judicial. Construcción y régimen narrativo”, J. Calvo González, en Rivista Internazionale di Filosofia del Diritto, IV Serie, LXXVI, Fasc.1, 1999, pp. 27-54. También en Id., Octroi de sens. Exercices d’interprétation juridique-narratif, Les Presses de l'Université Laval, Québec, 2007].
} 


\section{EL TIEMPO DE LOS DERECHOS DISPARA NUEVAS Y DISTINTAS CONTROVERSIAS JURÍDICAS}

Los derechos fundamentales se han convertido en el eje para pensar lo jurídico desde que alcanzaran consagración a nivel internacional, constitucional y legal durante la segunda mitad del siglo XX en buena parte del mundo.

Hoy hablar de derechos “fundamentales" es co-extensivo con hablar en términos de democracia radical.

Los fundamentos de esos derechos llevan décadas en discusión y otro tanto sucede con las vías o caminos para efectivizarlos y continuar ampliándolos; porque calificar de fundamentales a algunas normas u ordenamientos no alcanza, y argumentar desde alguna concepción filosófica, ética, religiosa o política tampoco ${ }^{5}$.

Los ordenamientos jurídicos necesitan siempre una justificación y la posibilidad de imponerse más allá de los conflictos. Esa justificación en la visión positivista antigua o actual no proviene de un ámbito filosófico, ético o religioso sino de su propia estructura. La positivación del derecho lleva esa procura, haciéndolo depender, sobre todo en el positivismo tradicional, en forma fundamental del poder político. Al mismo tiempo, como pensaba Rousseau, el derecho debía limitar el poder de la política.

Luhmann sostiene, con acierto, que garantizar los derechos fundamentales refuerza la fe en el Estado cuyo poder aumenta. Además, el derecho no solo protege a los individuos contra el Estado, sino que estructura el ambiente de la democracia para consolidar al Estado como subsistema social y hacer posible una actividad comunicativa más eficaz e influyente. El poder limitado entonces se vuelve más potente; lo que hace de los derechos fundamentales no solo una conquista del ciudadano, sino también del Estado ${ }^{6}$.

En el campo de los derechos humanos algunas discusiones iniciales han quedado abandonadas: la distinción entre derechos fundamentales y derechos humanos se reduce a palabras y significados (problemas del uso del lenguaje); la alusión a generaciones de derechos o la de derechos

${ }^{5}$ Conf. Gianluigi Palombella, “La autoridad de los derechos”, Ed. Trotta, Madrid, 2006.

${ }^{6}$ Conf. Niklas Luhman, “Il diritto fondamentale come Instituzione”, Ed. Dédalo, Bari, 2000. 
operativos o programáticos y la idea de que es posible diferenciar entre un núcleo duro de los derechos humanos y una periferia difusa en la que se ubican por ejemplo, los derechos sociales.

Los derechos humanos son el resultado de luchas sociales y políticas, la proyección de esos derechos al futuro es azarosa y contingente, abierta a múltiples posibilidades (ampliación, afirmación, transformación, crisis, extinción). Los derechos humanos son una conquista de la modernidad; se incrementan con la complejidad, los cambios de las relaciones sociales y el paso del tiempo; y mantienen un vínculo inescindible con el modelo de Estado moderno y más precisamente, con el Estado social de derecho.

Otra discusión frecuente refiere al carácter universal o relativo de los derechos fundamentales. Como ha dicho Ernesto Laclau, el universalismo es sólo un particularismo triunfante que deviene hegemónico y crea las representaciones del mundo que le resultan funcionales. Estamos en el siglo XXI, convivimos en la globalización, que nos ha permitido entender las diferencias, provenientes de tradiciones, culturas e historias heterogéneas. Los seres humanos tienen muchos denominadores comunes, pero practican distintas religiones, ingieren alimentos muy diversos, tienen distintas filosofías, poseen sistemas de representaciones acerca de lo bueno y lo malo, de la sexualidad y de la higiene que no son homologables.

Los argumentos éticos, jurídicos, filosóficos y religiosos que se exponen para “fundar” los derechos humanos pueden ser leídos desde una perspectiva crítica, como prioridades y políticas selectivas que privilegian unos valores por sobre otros en el juego de múltiples relaciones de poder. La confrontación de ideas y prácticas es factible en un marco de equilibrio y sensatez democrática. Afirmar lo contrario es investir al poder de burda inmoralidad: te prometo, pero para no darte.

A los occidentales puede parecerles propio de la naturaleza humana, el valor igualdad, pero si quieren ser respetuosos de la igualdad de otras culturas, debieran aceptarlas con sus diferencias y particularismos. Lo opuesto sería fatalmente contradictorio.

Estos temas han sido especialmente discutidos por dos corrientes teóricas de fuerte influencia en el ámbito anglosajón, en la perspectiva del liberalismo democrático. La historia comienza, posiblemente, con la aparición de la celebrada obra de Herbert Hart "El Concepto del 
Derecho” (Abeledo-Perrot, Bs. As., 1963), cuyas ideas tuvieron un rápido y generalizado impacto y en cierto sentido desplazaron los ejes impuestos por la perspectiva kelseniana.

Tres o cuatro años más tarde comienzan a conocerse los ensayos críticos de Ronald Dworkin que, desde mediados de los sesenta, escribe y debate infatigablemente, hasta su muerte, recientemente acaecida. En controversia plena con las posiciones de Hart, que derivan hacia el llamado convencionalismo e incluyen a un conjunto grande y destacado de discípulos como Coleman, Lewis, Postema, Marmor, Shapiro, Bratman, entre muchos otros.

\section{1}

El problema de la garantía de los derechos humanos y de la responsabilidad del Estado en la materia evoca la disputa ya lejana entre Kelsen y Schmitt sobre quién es el guardián de la Constitución.

Se trata ahora de resolver el papel que debe atribuirse a los distintos poderes del Estado en la custodia, construcción y control del despliegue individual y social de los derechos fundamentales.

Las tesis más radicales en contra del control de legalidad y legitimidad por parte de los jueces en relación con la producción legislativa, las viene sosteniendo el autor neozelandés Jeremy Waldron.

El autor piensa- en eso estamos de acuerdo- a la política como conflicto, lo que genera innúmeros desacuerdos en la vida social, cuya relevancia es mucho mayor que la que le reconocen las visiones liberales clásicas.

Pero el propio Waldron excluye los desacuerdos vinculados con los intereses, y no quiere entrar en la cuestión de las diferencias sociales y de la desigualdad, a pesar de que sostiene su preocupación por la dignidad humana y la autonomía de las personas. Sin embargo, como dirían Peces Barba o Ferrajoli o Sen, sin igualdad no hay libertad y sin libertad no hay dignidad.

En oposición franca a esta postura y tomando el ejemplo más próximo de nuestra experiencia nacional y latinoamericana, diré que es un recurso retórico "malicioso" denominar “contramayoritario” al Poder Judicial. Podría denominárselo “no mayoritario”, pero al decir contramayoritario parece indicarse que siempre está contra las mayorías, lo que es obviamente falso. 
El Poder Judicial no es “contramayoritario” como sostiene Waldron. El proceso de selección de los magistrados suele incluir en diversas etapas la opinión y decisión de parlamentarios, al principio y al final del procedimiento mediante el cual serán seleccionados. En ese procedimiento, por lo general, intervienen representantes de los tres poderes del Estado y también abogados y académicos.

Por otro lado, las representaciones parlamentarias. ¿Son éstas realmente elegidas por los votantes o las listas de candidatos (sábanas) se forman en el seno de las burocracias partidarias y los ciudadanos solo tienen como opción “take it or leave it”?

El sistema de sanción y subsiguiente control de la legalidad y legitimidad de las leyes resulta de la participación en distintos grados e instancias de la actividad complementaria de los tres poderes, con más el control de la sociedad civil que tiene posibilidad de intervenir en las audiencias públicas y producir impugnaciones o denuncias durante el proceso. Esto parece responder adecuadamente a los requerimientos de la sociedad compleja.

Todo lo anterior no significa, ni de lejos, apostar al gobierno de los jueces. Ya se ha visto, en los últimos tiempos, cuán negativas consecuencias ello puede implicar. Se trata de que la democracia de nuestro tiempo, demanda pluralidad y coordinación que no puede quedar en manos de un solo poder.

\section{2}

Por último, la más compleja y gravitante de las polémicas que el tiempo de los derechos, como lo hemos denominado, parafraseando al gran Norberto Bobbio, ha desplegado con abundante producción bibliográfica, es la que divide a “convencionalistas” por un lado, y “hermenéuticos” por el otro. Como siempre ocurre, estas denominaciones no son necesariamente precisas, pero cuando ganan aceptación generalizada, facilitan los intercambios argumentativos.

Ya se ha visto que H. Hart alcanza gran influencia con su obra "El Concepto de Derecho", al inicio de los 60. Desde su perspectiva los fundamentos de las proposiciones jurídicas son determinados por criterios compartidos acerca del uso del propio concepto de derecho. Elabora la 
muy divulgada noción de "regla de reconocimiento", mediante la cual los súbditos identifican un cierto núcleo de normas básicas y a los órganos instituidos que con recurso a dicha regla, podrán intervenir en la producción y aplicación del derecho. La regla de reconocimiento no surgiría de convenciones específicas, sino de comportamientos coordinados y complementarios de los individuos. La idea de Hart que tiene un fundamento socio-antropológico, coincide con las investigaciones de Arthur Gehlen y con las nociones desarrolladas mucho antes por David Hume, para quien las reglas que explican lo jurídico, no poseen un fundamento natural, racional o de naturaleza presocial, sino convenciones humanas (conf. G. Postema). Tales convenciones que no son acuerdos explícitos y formales, sino un sistema de comportamientos coordinados, surgen para resolver problemas propios de la interacción humana. No se trata de promesas recíprocas, sino de expectativas de conducta generalizadas. Concepto que N. Luhmann prácticamente homologa en su definición de derecho, con la que también coincide Habermas.

En el tránsito de “El Concepto de Derecho” al “Postscritum”, texto en el que Hart contesta las críticas de R. Dworkin, la noción de “convencionalismo”, como regularidades sociológicas que resultan de la vida social, recibe de su parte plena aceptación.

Al concluir esta "jibarizada” presentación del convencionalismo, no puede obviarse un singular mérito de Hart. A él le cupo introducir en el campo de la teoría jurídica el “giro lingüístico”, apoyado en el primer Wittgenstein.

Con ello amplió y enriqueció significativamente su problemática y puso en discusión cuestiones que el positivismo lógico había dejado de lado: el tema de la objetividad y el conocimiento como representación, por ejemplo.

El impulso que la filosofía del derecho gana con el aporte hartiano y el de sus discípulos, no protege sin embargo al convencionalismo, de las perseverantes e implacables críticas y objeciones que le dispensan Ronald Dworkin y sus seguidores, mediante una estrategia discursiva sin duda afortunada, pues consiguen, en particular Dworkin, tratar con claridad arduos núcleos filosóficos y referirse siempre a temas que interesan necesariamente a juristas prácticos, abogados y jueces. Desde los alcances de la democracia hasta el aborto, la eutanasia, el sistema de salud, etc. Además, claro, de las cuestiones más teóricas sobre el concepto de derecho, la hermenéutica, la normatividad, los principios, la moral y en general sus muchas perspectivas innovadoras. 
En “El modelo de Reglas I”, Dworkin dice que, a pesar de intentar describir el derecho Hart, no lo hacía de manera adecuada, pues la regla de reconocimiento no podía tener sólo una dimensión fáctica, sino también valorativa. Dado que al lado de las normas jugarían su papel los principios, toda interpretación jurídica contendría argumentación moral. Las razones para la acción, sostiene, no implican mera coordinación compartida de conductas, sino también de valores. Este aspecto pone en crisis la separación positivista entre derecho y moral.

La deriva de esta confrontación produjo alto impacto en el positivismo, al punto de generar una ruptura entre quienes se mantenían consistentes con sus posiciones tradicionales (Raz) y quienes reconocían alguna razón a la crítica dworkiana. De ahí la emergencia de un positivismo excluyente: “el derecho y la moral son órdenes distintos de fronteras infranqueables” y un positivismo incluyente, que admite cierta capilaridad en la frontera

Desde la perspectiva de Dworkin el convencionalismo falla al tratar la dimensión argumentativa del derecho, que él concibe, precisamente, como una práctica social de esa índole; falla al describir la normatividad que las prácticas exhiben; no describe acertadamente la tarea interpretativa de los jueces; no advierte que los individuos usan normativamente, leguaje moral en el ámbito jurídico.

Hasta aquí he tratado de describir una parte importante de los debates actuales sobre el derecho que constituyen al mismo tiempo, un cierto modo de racionalidad, como se ha visto, en el marco de serias discrepancias. Lo he hecho, intentando no deformarlas. En verdad no me fue difícil, pues las posiciones expuestas precedentemente padecen a mi juicio de una grave enfermedad que podría denominarse miopía liberal severa. Ellas refieren a los derechos y al juego de las instituciones democráticas, con notoria y casi sorprendente abstracción respecto de las cruciales diferencias existentes en las sociedades humanas reales. Asimetrías sociales, económicas, étnicas, culturales, de género, de opción sexual, etc. Los grupos que interactúan, no coordinan sus acciones ni en función de expectativas compartidas, ni de principios morales que puedan considerarse comunes a todos ellos. Interactúan en el marco de sus propias identidades y mediante estrategias a partir de las cuales, defienden sus intereses y visiones del mundo. En la interacción social hay una marca indeleble de conflictualidad. 
El valor igualdad es el principio iluminista que menos hemos conseguido concretar y como dicen los pensadores igualitaristas que he mencionado y otros que no he mencionado, sin igualdad no hay libertad. La igualdad es la condición de posibilidad de la libertad, pero lo cierto es que vivimos en sociedades abominablemente discriminatorias, discriminación que se materializa desde el poder, la violencia, el prejuicio, el egoísmo acaparador. Con el mayor respeto ¿no precisa ese ambiente teórico de un “oftalmólogo de los valores”? ¿No perciben estos autores la realidad de la miseria, la exclusión y la marginalidad; de la discriminación racial; o de género, etnia o religión; no les llegan los ecos de las bombas arrojadas sobre poblaciones civiles en Irán e Irak, ni tienen noticia de los incontables femicidios o de las lapidaciones de mujeres que ocurren día en el mundo; ni del aumento repentino de las endemias que creíamos superadas hace ya años? ¿Será que el derecho, los derechos, el Estado, las instituciones, las deliberaciones, no tienen incumbencia en estas cuestiones o son en cambio el único camino racional (uso la expresión ex profeso), el camino regio para construir sociedades humanas más justas, más equitativas y más libres?

Es claro que hay otras líneas de pensamiento a las que no hemos aludido. En la tradición anglosajona el Movimiento de los Critical Legal Studies, autores como Neil McCormick, Stanley Fish, Owen Fiss, Robert Post, Reva Siegel o Jack Balkin; y muchos otros. Y luego los europeos más emblemáticos: Ferrajoli, Foucault, Habermas, mencionados a efectos metonímicos, las teorías sistémicas, las líneas controvertidas y ricas de naturaleza argumentativa de muchos españoles e italianos, de portugueses como Boaventura de Sousa Santos y otros, el pensamiento latinoamericano. Quiero decir, hay juristas que no se escapan del mundo e intentan lidiar contra sus peores rostros.

\section{EL PUNTO DE VISTA DE LA TEORÍA CRÍTICA}

Como es conocido el punto de vista crítico se ha diferenciado de las líneas teóricas tradicionales en el campo de la jusfilosofía por enfatizar, básicamente, dos cuestiones. Por un lado, la necesidad de “despurificar la teoría”, como decía Luis Warat. Es decir, la necesidad de entender el derecho como un fenómeno de naturaleza y estirpe social, alejado de las visiones objetivistas de las ciencias naturales y de las visiones puramente deductivistas de las ciencias formales. Asumiéndolo como un producto histórico de la evolución de las sociedades humanas, constitutivo de la construcción de sentido en la interacción social, en intercepción y cruce permanente con diversas dimensiones de la socialidad; con la economía, con la política, con el poder, con la ideología, con la moral, y la apuesta a una renovada visión epistémica. Por otro, todo conocimiento crítico, desde 
Heráclito para acá es visto como conocimiento interviniente. Esto es, al desplegarse sobre el objeto que tematiza lo modifica, lo recompone, lo transforma. La objetividad del conocimiento en el campo social es intersubjetividad y el lugar del observador en el campo, su perspectiva diría Husserl, no es indiferente al modo en que aquel puede aprehender el objeto que observa. Reductivamente planteados, estos presupuestos epistémicos cercanos a algunas tradiciones comprensivistas, en particular la de Alfred Schütz y a algunos presupuestos sistémicos, explican el modo y las finalidades de las intervenciones teoréticas de la crítica jurídica. En la actualidad, esta corriente está particularmente interesada en los desarrollos que ha realizado el Movimiento denominado "Law and literature”, específicamente en los autores del enfoque denominado “Law as literature”. En otros términos, en el punto de vista de quienes piensan que constituye un aporte valioso y además insoslayable, incorporar los desarrollos contemporáneos de la semiótica y de sus múltiples ramas, a la teoría jurídica. Entre aquellas ramas aludo a la teoría del discurso, a la semiótica del texto, a la narratividad, a la teoría de la recepción, etc.

Hart, como ya dije, enriqueció la teoría con las ideas del primer Wittgenstein, pero la tradición positivista se preocupó por los lenguajes formales y no por los naturales. Prefirió la textualidad, no prestó atención al segundo Wittgenstein ni a su preocupación por los usos del lenguaje y por la pragmática de la Comunicación; y así olvidó o ignoró que los problemas del lenguaje se alojaban también en unidades de sentido más complejas que las palabras; de forma particular aunque no excluyente en lo que al derecho concierne, en los textos. Y los textos ofrecen además de los problemas ya conocidos otros, de los que se ocupan numerosas disciplinas que, por cierto, no se enseñan en las Escuelas de Derecho, salvo raras excepciones. Por citar sólo algunas a manera de ejemplo: a) la autoreferencialidad del lenguaje: con palabras hablamos entre otras cosas de palabras, construimos textos que tienen por objeto de reflexión otros textos, lo cual obliga a distinguir niveles del lenguaje y hacerse cargo de problemas que la lingüística estudia, pero el derecho no, como son los de intertextualidad, paratextualidad, contextualidad, etc. b) el sentido circula al interior de los textos bajo la forma de tropos del lenguaje, esto es, metáforas, sinécdoques y metonimias, que implican desplazamientos de sentido. De modo, cada acto de lectura, aun el que el mismo sujeto pueda realizar en forma más o menos sucesiva, reaviva el sentido, lo que lo torna potencialmente diferente, porque el sujeto no es el mismo sujeto, en cada nuevo acto de lectura y porque los contextos y los paratextos pueden venir a jugar su misión rearticuladora. 
En el diseño propuesto por el paleo positivismo aplicar la ley era cuestión de lectura y deducción lógica. En la medida de lo posible, había que entender los textos de la manera y con el sentido con que ellos habían sido sancionados oportunamente (en USA el llamado “originalismo”) y en caso de dudas, aplicar el método interpretativo “correcto”, que no sería otro que aquel que condujera a desentrañar la "verdad” de la o las normas aplicables, partiendo además de la premisa de que saber en cada caso cuál era la norma o set de normas aplicable, resultaba una cuestión naturalmente obvia. Kelsen que se animó a afirmar tempranamente que el acto de adjudicación no era sólo un acto de conocimiento, sino también de voluntad, escandalizó a la Academia y tuvo, en los hechos, esto es, en los Tribunales, poca influencia. Más allá de su innegable talento, él mismo no es ajeno al reproche. Fue precisamente su concepción acerca de la pureza metódica del derecho, lo que aisló la teoría jurídica de la teoría social y de las humanidades, artificiosa y arbitrariamente, de modo que esta última llega tarde al encuentro de problemáticas que tienen larga historia en disciplinas como la filosofía, la historia o la antropología.

Los lingüistas nos han explicado que no existe estabilidad del signo, es decir, que las palabras no dicen siempre lo mismo y que el sentido del que son portadoras se modifica y transforma en términos históricos, científicos, políticos, valorativos, etc., al hilo de las propias transformaciones sociales. Ello implica que la pretensión de leer siempre el mismo texto, es ilusoria. Por otra parte el texto no se autoabastece. Es mudo, no dice que es lo que dice. Necesitamos un lector. No hay texto sin lector, dice Umberto Eco. Del mismo modo cabe afirmar que no hay norma sin intérprete; no hay derecho sin jueces o cualquier otra denominación que le otorguemos a los aplicadores. El derecho se vale permanentemente de expresiones que son lábiles semánticamente: buen padre de familia, mujer honesta, salario justo, vivienda digna, debidos cuidados. El legislador o el juez deben explicitar sentidos, concretar significaciones y por cierto, lo hacen en términos sociales y no solipsísticos, porque como decía Wittgenstein, toda interpretación es social. Por cierto tal circunstancia les atribuye un enorme poder político, pero como he sostenido en otro texto ${ }^{7}$, una visión del proceso y por ende de la adjudicación, que desmonta ficticias seguridades al no presentarlo ya como el resultado de prolijos y aceitados mecanismos lógicos y nos lo devuelve, en cambio, como compleja construcción discursiva, problemática y azarosa, no escapa, sin embargo, a los marcos de sutiles entramados de racionalidad y razonabilidad, que la cultura occidental ha construido por siglos. Siglos de refinamiento de las tecnologías jurídicas, siglos de socialización producida por las escuelas de

${ }^{7}$ Ficción y verdad en la escena del proceso, en “Las Teorías Jurídicas post positivistas”, Abeledo Perrot, Buenos Aires, 2012. 
derecho, siglos de un saber especializado, siglos de una cultura "tribunalicia”. Las actuales perspectivas teóricas, no implican irracionalidad, sino otra racionalidad, al colocar en distinto marco conceptual el análisis de algunas problemáticas tradicionales e inducen a explotar el enorme desarrollo de la lingüística contemporánea.

\subsection{OTRA EPISTEMOLOGÍA; MÁS SEMIÓTICA}

El advenimiento de las llamadas nuevas ciencias (teoría de sistemas, cibernética, neurociencias, autopoiésis) vino a proponer una nueva perspectiva epistemológica, denominada por lo general como "constructivismo radical"8. El conocimiento deja de ser entendido ahora, como una representación mental de la realidad y la conciencia como un “espejo de la naturaleza”. Dado que toda realidad no inefable es “realidad comunicada”, es preciso entender que lo que está afuera de la conciencia de los sujetos, es algo más que pura externalidad, es también comunicación, esto es, construcción de sentido. Lo que está “afuera”, lo “real”, lo “objetivo”, adquiere esa condición, en un proceso de intercambio comunicativo que lo constituye como real, porque resulta mediado por palabras, por significaciones, por historias previas, por símbolos, por valoraciones, por acuerdos, por precomprensiones del mundo.

Desde una tal epistemología, resulta claro que la perspectiva de una interpretación unívoca o mecánica aparece como ingenua o ideológica. La interpretación unívoca remite al formalismo, al mecanicismo, al universalismo, es decir, a todo aquello que la nueva epistemología y la crítica jurídica han venido a poner en cuestión. Dado que el derecho puede concebirse como la más importante estructura de comunicación y de interacción social del mundo que nace con la modernidad, parece claro que entender su específica forma de organización, su carácter textual y no textual, la manera en que operan al interior del discurso que le es propio, las nociones de código, mensaje, recepción, demandan estudios de semiótica general y de semiótica jurídica. La complejidad de esta problemática, al mismo tiempo filosófica, epistémica y disciplinaria, también recusa la posibilidad de una interpretación pacífica, ineludible y transparente de los textos normativos.

8 V. entre otros, Ernst Von Glasersfeld, “La Construcción del conocimiento” en "Nuevos Paradigmas, Cultura y Subjetividad”, Paidos, Bs. As., 2002, p- 91 y ss. 


\subsection{LA TEORÍA DEL DISCURSO}

Los estudios del discurso han resultado de enorme interés para las ciencias sociales contemporáneas y aunque reconstruir una noción precisa, resulte una empresa compleja por la extrema multivocidad del término, es posible desde una perspectiva digamos “técnica”, entender al discurso como un acontecimiento comunicacional, interacción verbal o proceso social de producción de sentido. Se trata del análisis de quién utiliza el lenguaje, cómo lo utiliza, para qué y cuándo, de modo de poder formular una teoría sobre las relaciones entre el uso del lenguaje y las creencias, en el marco de la interacción social.

Desde un punto de vista estructural el discurso consiste en una secuencia proposicional, dispuesta en un cierto orden. Gestos, movimientos, posturas, volumen elocucional, completan el sentido de la interacción verbal; cuando la interacción es textual, la intertextualidad y la contextualidad, cumplen igual misión. Finalmente el sentido alude siempre a ciertas representaciones semánticas.

El análisis del discurso atiende, además de las reglas semánticas y sintácticas, las formas deliberadas o no, con las que los usuarios se comunican a través de procesos estratégicos. Las representaciones mentales que provienen de la lectura de un texto o de la escucha, no constituyen reproducciones mentales mecánicas, esto es, no copian sentidos portados en los mensajes, sino que deconstruyen y reconstruyen sentido, utilizando elementos conversacionales, textuales y contextuales, conjuntamente con el conjunto de creencias que los usuarios ya poseen antes de iniciar la comunicación. Y así como el contexto influye en el discurso, éste puede modificar el contexto. Como explica con acierto Teun A. van Dijk, cuyas ideas parafraseamos

...en todos los niveles del discurso encontramos "huellas" de un contexto en el que las características sociales de los participantes desempeñan un papel fundamental, se trate del género, la clase, la filiación étnica, la edad, el origen, la posición u otros rasgos que determinan su pertenencia a un grupo. ${ }^{9}$

Estas notas deben concluir aquí, pues ya han excedido la extensión adecuada. Tal como se ha expuesto en este último apartado, el enfoque crítico postula una racionalidad distinta como marco actual para la aprehensión de la problemática jurídica. Ella parte de presupuestos epistemológicos que asocian conceptos comprensivos y constructivos; piensa al derecho como

\footnotetext{
${ }^{9}$ Aut. Cit. El estudio del discurso, en El discurso como estructura y proceso, Gedisa, Barcelona, 2000, p. 43 ss.
} 
producto histórico, positivo, público y social; señala el conflicto y la contradicción entre grupos hegemónicos y grupos subordinados en la estructura social, como dato constitutivo de lo jurídico, que cumple una función paradojal: a la vez que sirve para dar estabilidad y reconduce ciertas formas de distribución del poder, sirve también, en contextos democráticos, para transformar las relaciones de poder con sentido progresivo ${ }^{10}$.

Atribuye centralidad a las cuestiones del lenguaje y a los desarrollos de la semiótica y concibe al derecho como una práctica social discursiva, es decir, productora de sentido. Sentido que se aloja en los textos, en las interpretaciones y en las representaciones sociales acerca de los mismos y también en prácticas materiales: arquitecturas, sitiales, togas, embanderamientos etc. Como se advierte nos alejamos de las versiones tradicionales de la teoría, pero también nos acercamos a muchos de sus planteamientos. Como Dworkin, enfatizamos el papel de la hermenéutica y creemos que el debate acerca del sentido de las normas implica contenidos morales vigentes en una determinada cultura de época. Como Hart sostenemos que el derecho es creación humana y positiva. Como, Kelsen que los jueces crean derecho y que sus funciones específicas y las características propias del lenguaje les otorga un poder que, señalamos no se hipertrofia porque sobre ellos pesan determinaciones y limitaciones que provienen de distintos niveles de la estructura social. Ya hemos expuesto nuestras importantes diferencias.

Lo cierto es que el debate contemporáneo se ha enriquecido y los esclarecimientos que él produzca, serán sin dudas, en consecuencia, más fructíferos. Esto cabe esperar, que una racionalidad humana, hermanada con los valores de una sociedad libre e igualitaria nos permita alejar rápidamente los nubarrones que en los últimos tiempos se han cernido sobre nuestros países.

Muchas gracias.

\footnotetext{
${ }^{10}$ V. C. M. Cárcova “Análisis Funcional del Dcho.” En “Las Teorías Jurídicas post positivistas” Ed. Abeledo-Perrot, Bs. As., 2012.
} 